\title{
Supply Chain Governance Tensions: A Qualitative Exploration of Business-to- Business Relationship Structures
}

\author{
Frank G. Adams, V. Myles Landers, and Colin B. Gabler
}

\begin{abstract}
How and why firms jointly compete to achieve superior performance has been examined in marketing strategy by both relational governance and supply chain management scholars, who have approached the issue from different perspectives and offered different, but not necessarily exclusive, findings. Recent efforts to reconcile their theories and results suggest looking at the issue from a broader perspective. Based on a qualitative study of managers that interface with their firm's trade partners, the authors propose a framework that views relational governance and supply chain management constructs as a combination of unilateral capabilities, collaborative capabilities and environmental factors.
\end{abstract}

\author{
F.G. Adams \\ Mississippi State University, Starkville, MS 39762, USA \\ e-mail: fadams@business.msstate.edu \\ V.M. Landers $(\bowtie)$ \\ Rochester Institute of Technology, Rochester, NY 14623, USA \\ e-mail: vlanders@saunders.rit.edu \\ C.B. Gabler \\ Ohio University, Athens, OH 45701, USA \\ e-mail: gabler@ohio.edu
}

